\title{
Tiam1, overexpressed in most malignancies, is a novel tumor biomarker
}

\author{
BIN CHEN $^{1 *}$, YI DING ${ }^{2 *}$, FEIYE LIU ${ }^{3}$, JIAN RUAN $^{3}$, JIAN GUAN $^{2}$, JING HUANG $^{2}$, \\ XIANGHUA YE ${ }^{2}$, SHUANG WANG ${ }^{4}$, GONG ZHANG $^{5}$, XIANGMEI ZHANG ${ }^{4}$, \\ ZHAO LIANG ${ }^{4}$, RONGCHENG LUO ${ }^{3}$ and LONGHUA CHEN ${ }^{2}$
}

${ }^{1}$ General Hospital of Guangzhou Military Command of PLA, Guangzhou, Guangdong 510515; Departments of ${ }^{2}$ Radiotherapy, and ${ }^{3}$ Oncology, Nanfang Hospital; ${ }^{4}$ Department of Pathology, School of Basic Medical Sciences;

${ }^{5}$ Cancer Research Institute, Southern Medical University, Guangzhou, Guangdong 510515, P.R. China

Received June 26, 2011; Accepted August 31, 2011

DOI: $10.3892 / \mathrm{mmr} .2011 .612$

\begin{abstract}
T lymphoma invasion and metastasis 1 (Tiam1) is a guanine nucleotide exchange factor (GNEF) family member, and is considered to be involved in many important cellular processes and oncogenesis. In this study, we investigated Tiam1 expression differences between normal tissue and malignant tissue using tissue microarray (TMA), and further studied the Tiam $1 \mathrm{mRNA}$ and protein level in 9 hepatoma lines. Fortynine tumor tissue and 47 normal tissue samples were detected via TMA by immunohistochemistry with polyclonal antibody. Tiam1 expression in 9 human hepatoma cell lines, namely Huh-7, HepG2, Hep3B, SMMC-7721, QGy-7701, QGy-7703, BEL-7402, BEL-7404 and BEL-7405, and 1 normal primary human hepatocyte, HL-7702, was compared by means of fluorescence quantitative PCR, immunocytochemistry assay and Western blotting. We found that Tiam1 was significantly expressed in various malignancies. Tiam1 mRNA and protein levels were significantly elevated in the 9 human hepatoma cell lines compared to the normal primary human hepatocyte. Our results suggest that Tiam1 overexpression in malignant neoplasms could be a novel effective supplementary biomarker for tumors, including hepatocellular carcinoma.
\end{abstract}

Correspondence to: Dr Longhua Chen, Department of Radiotherapy, Nanfang Hospital, Southern Medical University, Guangzhou, Guangdong 510515, P.R. China

E-mail: chenlhsmu@126.com

Dr Rongcheng Luo, Department of Oncology, Nanfang Hospital, Southern Medical University, Guangzhou, Guangdong 510515, P.R. China

E-mail: luorc0001@126.com

${ }^{*}$ Contributed equally

Key words: T lymphoma invasion and metastasis 1, tumor biomarker, tissue microarray, hepatocellular carcinoma

\section{Introduction}

T lymphoma invasion and metastasis 1 (Tiam1) gene, located on human chromosome 21 or murine chromosome 16, is a member of the guanine nucleotide exchange factor (GNEF) family and has been found to be an important gene contributing to cellular functions, such as cell adhersion, immigration, invasion and metastasis (1). It contains several important structures which can specifically activate Rho GTPase family member Rac1 in vivo and in vitro, and is thus closely involved in tumor invasion and metastasis. It has previously been reported that Tiam1 is highly expressed in T lymphoma, B lymphoma, pancreatic carcinoma, breast, bladder and lung carcinoma (2). However, a relatively comprehensive study as regards its expression in normal and tumor tissues has yet to be published. There have also been no reports regarding Tiam1 gene or protein expression in hepatoma. The cellular localization of Tiam1 in normal and tumor tissues is currently unclear. In this study, we detected the localization and expression of Tiam1 in both normal and tumor tissues with immunochemistry and tissue microarray (TMA), and analyzed the expression pattern of Tiam1 as well as its potential of being a tumor biomarker. According to the acquired results, we particularly investigated the expression of Tiam1 in hepatoma.

\section{Materials and methods}

Tissue samples. Paraffin-embedded tissue blocks from 2002 to 2007 were collected to construct TMAs obtained from the Southern hospital (Guangzhou, China), including 49 tumor tissue samples (from 34 male and 15 female patients) and 47 normal tissue samples (from 32 male and 15 female patients). Patient age range was $15-83$ years (median 54). None of the patients had undergone any chemotherapy or radiotherapy prior to surgical resection. All tissues were fixed with $10 \%$ neutral formalin and imbedded in paraffin.

Cell lines. The human hepatoma cell lines, Huh-7, HepG2, Hep3B, SMMC-7721, QGy-7701, QGy-7703, BEL-7402, BEL-7404 and BEL-7405, and the normal primary human hepatocyte, HL-7702, were obtained from the Academia 
Sinica Type Culture Collection (Shanghai, China) and cultured as recommended.

Tissue microarray. Briefly, we observed the morphology of H\&E-stained sections, which were made from each donor block, and marked representative tissue regions. Tissue cylinders $(0.6 \mathrm{~mm}$ in diameter) were then punched from the region of the donor block and placed into the recipient orifice. In total, the TMAs were composed of 192 tissue cores. The TMA blocks were cut into $4-\mu \mathrm{m}$ sections that were transferred to glass slides and kept at $4^{\circ} \mathrm{C}$. Sections from the TMA block were used for immunohistochemistry. The following human TMAs were included in this study: nasopharyngeal (squamous carcinoma), lung (squamous carcinoma and adenocarcinoma), esophagus (squamous carcinoma and adenocarcinoma), gastric (adenocarcinoma), colon (adenocarcinoma), rectal (adenocarcinoma), hepatoma, pancreatic (adenocarcinoma), breast (adenocarcinoma), renal cell cancer, cervix (adenocarcinoma), ovarian (adenocarcinoma), prostatic (adenocarcinoma), brain (neurogliocytoma), skin (squamous carcinoma), diffuse large $\mathrm{B}$ cell lymphoma and non-neoplastic tissues from a variety of 18 organs.

Immunochemistry assay. For immunochemistry, the sections were dried at $65^{\circ} \mathrm{C}$ for 2-4 h, then deparaffinized and rehydrated. Heated-induced epitope retrieval was carried out in $0.01 \mathrm{M}, \mathrm{pH} 6.0$ sodium citrate buffer in a microwave oven for $20 \mathrm{~min}$. Endogenous peroxidase activity was blocked with $0.3 \% \mathrm{H}_{2} \mathrm{O}_{2}$ methanol. Normal goat serum (5\%) was used to block non-specific staining. Incubation with primary antibody (rabbit anti-Tiam1; Santa Cruz Biotechnology) (1:100) was performed at $4^{\circ} \mathrm{C}$ overnight. After incubation with biotinylated secondary antiserum, the slide-mounted sections were stained with 3,3'-diaminobenzidine tetrahydrochloride and counterstained with hematoxylin. As described by Engers et al (9), staining intensity scaled from 0 (no staining) to 3 (strong staining), and staining extent scaled from $0(0 \%)$ to 4 (80-100\%). Immunoreactive scores were calculated by multiplying staining intensity score times staining extent score and divided into four groups: (-), 0-1; (+), 2-4; (++), 5-7; (+++), 8-12; $(-)$ and $(+)$ were considered as low expression, while $(++)$ and $(+++)$ were high expression.

Immunocytochemistry assay. The S-P immunohistochemistry method was used to detect the expression of Tiam1 in human hepatoma cell lines and normal primary hepatocytes with SP-9000 Histostain ${ }^{\mathrm{TM}}$-Plus kits according to the manufacturer's instructions. Serial cells were fixed in $90 \%$ ethyl alcohol for $10 \mathrm{~min}$ and incubated sequentially with $3 \% \mathrm{H}_{2} \mathrm{O}_{2}$ for $10 \mathrm{~min}$, normal goat serum for $10 \mathrm{~min}$ at room temperature, primary antibody (Tiam1 1:120; Santa Cruz Biotechnology) overnight at $4^{\circ} \mathrm{C}$, biotintylated secondary antibody (1:200; Santa Cruz Biotechnology) at $37^{\circ} \mathrm{C}$ for $30 \mathrm{~min}$ and avidinbiotin horseradish peroxidase for $10 \mathrm{~min}$, and reacted with 3,3'-diaminobenzidine for 3-10 min.

Western blotting. The cells were washed twice with cold phosphate-buffered saline (PBS) and then lysed on ice in RIPA buffer [1X PBS, $1 \%$ NP40, $0.1 \%$ sodium dodecylsulfate (SDS), $5 \mathrm{mM}$ EDTA, $0.5 \%$ sodium deoxycholate and $1 \mathrm{mM}$ sodium orthovanadate with protease inhibitors. Protein samples were resolved in 6\% SDS polyacrylamide gel, electrotransferred to polyvinylidene fluoride membranes and blocked in 5\% non-fat dry milk in Tris-buffered saline, $\mathrm{pH} 7.5(100 \mathrm{mM}$ $\mathrm{NaCl}, 50 \mathrm{mM}$ Tris and $0.1 \%$ Tween-20). Membranes were immunoblotted overnight at $4^{\circ} \mathrm{C}$ with anti-Tiam 1 antibody and anti- $\beta$-actin antibody (Santa Cruz Biotechnology), followed by their respective horseradish peroxidase-conjugated secondary antibody. Detection was performed by using an enhanced chemiluminescence kit (Sino-American Biotechnology).

Fluorescence quantitative PCR. In brief, total RNA was extracted using the TRizol Reagent (Invitrogen) and reversetranscribed using the reverse transcription system (Takara) according to the manufacturer's instructions. Quantitative PCR analysis was performed with the Mx3000P ${ }^{\mathrm{TM}}$ real-time PCR system (Stratagene) and SYBR-Green kit (Takara). The following pairsofprimeswereused:5'-AAGACGTACTCAGGC CATGTCC-3' and 5'-GACCCAAATGTCGCAGTCAG-3' for TIAM1; 5'-AAGACGTACTCAGGCCATGTCC-3' and 5'-AC TCGTCATACTCCTGCTT-3' for $\beta$-actin, which served as the internal control. The reaction was carried out in a $20 \mu \mathrm{l}$ volume containing $0.4 \mu \mathrm{l}$ of each forward and reverse primer $(10 \mathrm{mM})$, $1 \mu \mathrm{l}$ cDNA, $10 \mu \mathrm{l} \mathrm{SYBR}$ buffer and 8.6 $\mu \mathrm{l}$ DNase/RNase-free $\mathrm{H}_{2} \mathrm{O}$. The thermal profile was 45 cycles of denaturation for $40 \mathrm{sec}$ at $94^{\circ} \mathrm{C}, 40 \mathrm{sec}$ annealing at $56^{\circ} \mathrm{C}$ and $40 \mathrm{sec}$ extension at $72^{\circ} \mathrm{C} . \Delta \mathrm{Ct}$ values were obtained by formula calculation of $\mathrm{Ct}$ values according to the amplication curve of Tiam 1 and $\beta$-actin. The $\Delta \mathrm{Ct}$ values and $-\Delta \Delta \mathrm{Ct}$ values were analyzed using oneway ANOVA (LSD; Dunnett t-test), considering a value of $\mathrm{P}<0.05$ as statistically significant.

\section{Results}

Tiam1 protein expression in normal and tumor tissues. Eighteen types of normal tissues and 19 types of tumor tissues were included in this study. Generally, Tiam1 protein expression could not be observed in mammary gland fibrous tissue, pancreatic and hepatic tissue, while the other 15 normal tissues showed positive protein expression of different levels. Weak staining was observed in parts of the cells in the nasal epipharynx, lung, bladder, cervix, ovaries, lymph glands, skin and brain tissues. Weak or moderate staining was observed in parts of the cells in the membrane mucosa and fibrous smooth muscle tissues of the esophagus, stomach, colon and rectum. In the hyperplastic prostate gland, moderate staining was observed in the glandular epithelium, whereas diffused strong staining was seen in the proliferative smooth muscle. In the kidney distal convoluted tubule, strong staining of Tiam1 was observed in the epithelial and vessel wall smooth muscle cells (Fig. 1).

As regards tumor tissues, strong staining was observed in hepatoma, nasopharyngeal carcinoma, breast cancer, lung squamous carcinoma, lung adencarcinoma, colon carcinoma, rectal cancer, prostatic carcinoma, ovarian cancer and diffuse large B cell lymphoma cells. Weak staining was observed in esophageal carcinoma, gastric carcinoma, pancreatic cancer, suprarenal epithelioma, transitional cell carcinoma of the bladder, cervical cancer, pancreatic cancer, brain neurogliocytoma and cutaneous squamous cancer. In addition, we found weak or moderate staining of Tiam1 in para-carcinoma liver 

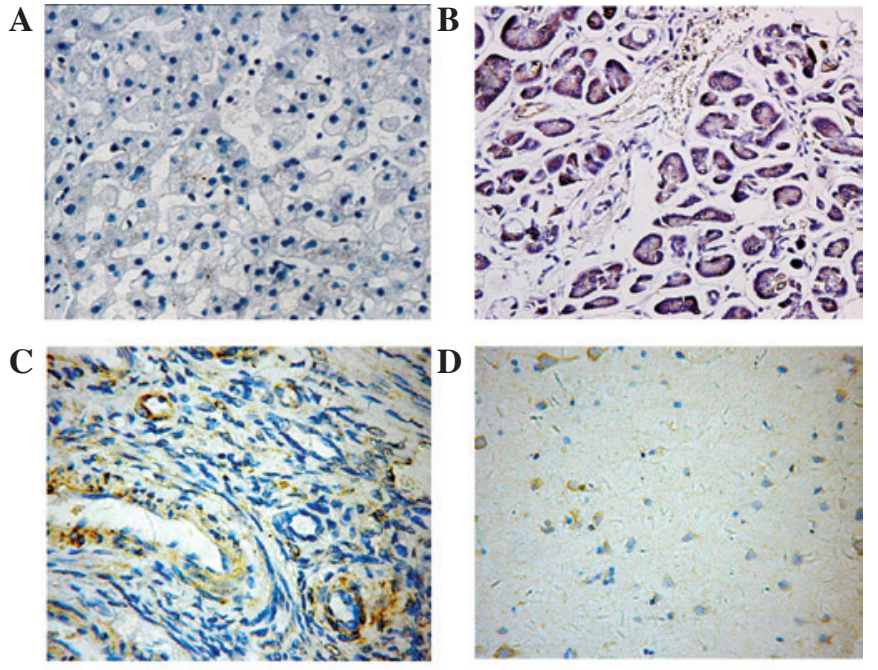

E
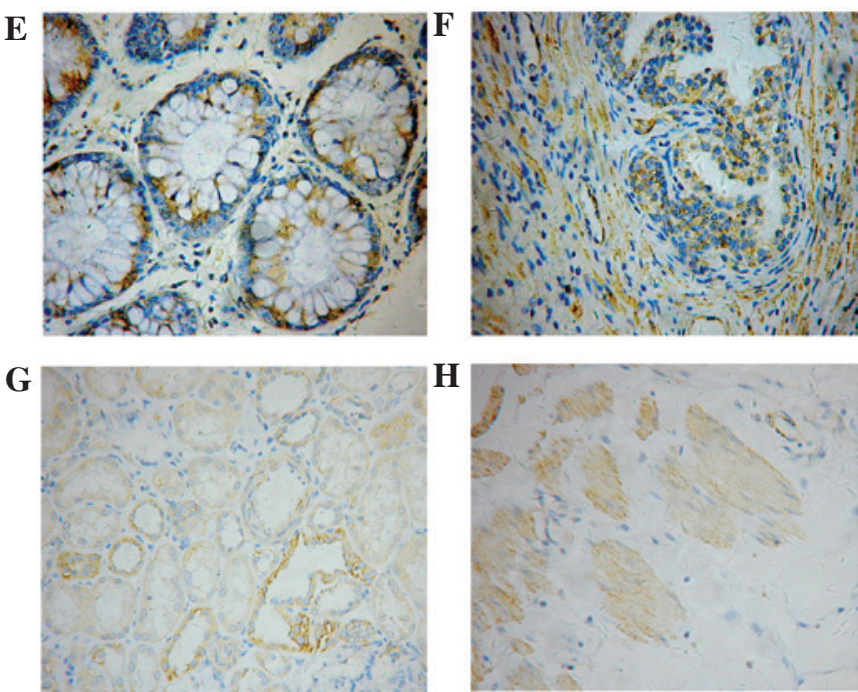

Figure 1. Expression of Tiam1 protein in human normal tissue (original magnification, x200). (A) Liver tissue, (B) pancreatic tissue, (C) ovarian tissue, (D) brain tissue, (E) intestinum rectal tissue, (F) proliferative glandular epithelial tissue of the prostate, $(\mathrm{G})$ epithelial tissue of the distal convoluted tubule, $(\mathrm{H})$ proliferative smooth muscle tissue of the esophagus.

sclerotic tissue and in proliferative liver interstitium (Fig. 2). Thus, hepatoma was chosen for further investigation.

Tiam1 expression in hepatoma cell lines. In immunocytochemistry assay, we defined buffy granules on the cell membrane or cytoplasm as Tiam1-positive expression, and no granules on the cell membrane or cytoplasm as Tiam1-negative expression. Significant Tiam1 expression was observed in the 9 hepatoma cell lines, but not in the normal primary human hepatocyte, HL-7702 (Fig. 3).

Tiam 1 protein and mRNA levels were detected by Western blotting and qRT-PCR (Figs. 4 and 5) in 9 human hepatocellular carcinoma cell lines and 1 normal hepatocyte. Of the 10 cell lines, the expression of Tiam1 in the 9 hepatoma cell lines was significantly higher than in the normal hepatocyte.

\section{Discussion}

The Tiam1 gene, first identified from murine T lymphoma cells, is a member of the GNEF family which plays a signifi-
A
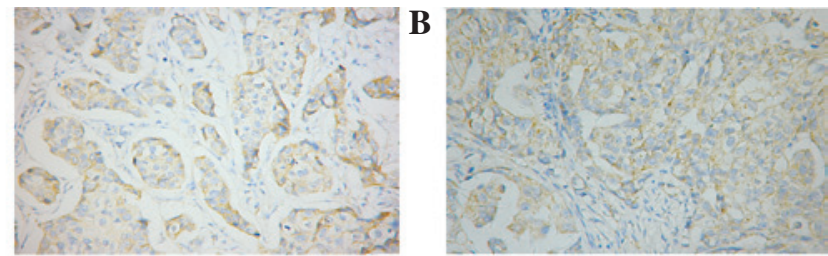

C
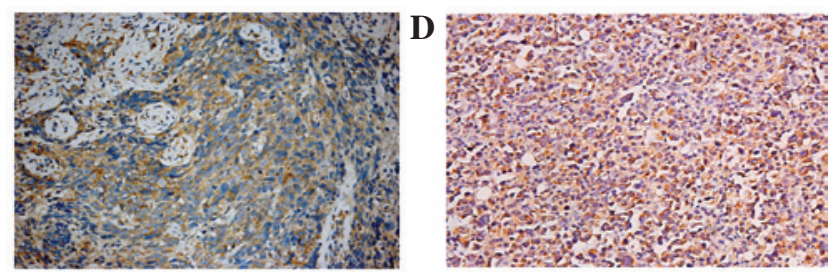

E
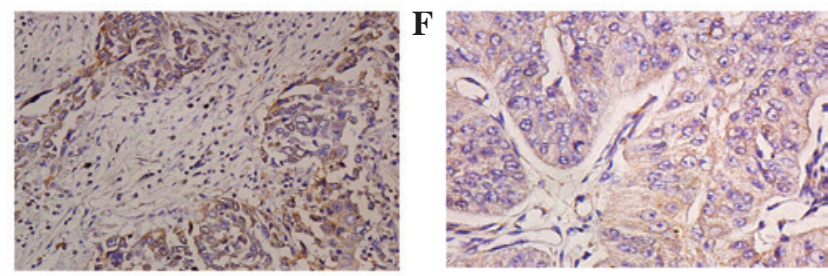

G
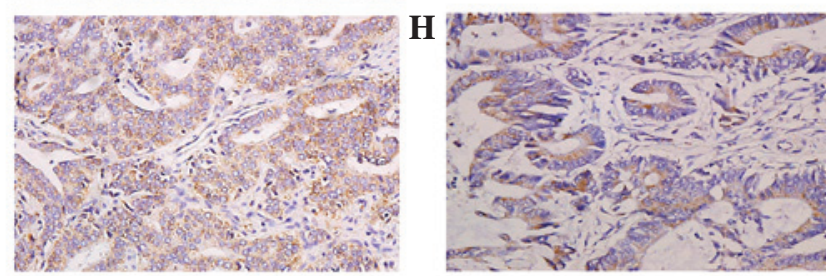

I
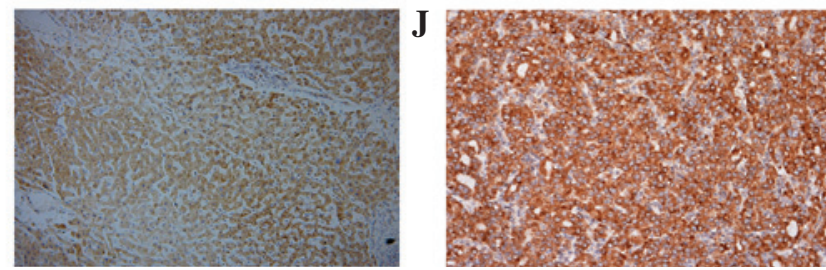

Figure 2. Expression of Tiam1 protein in human tumor tissue (original magnification, x200). (A) Breast cancer, (B) ovarian cancer, (C) nasopharyngeal carcinoma, (D) B cell lymphoma, (E) lung cancer, (F) carcinoma of the bladder, $(\mathrm{G})$ colon carcinoma, $(\mathrm{H})$ prostatic carcinoma, (I) hepatic cirrhosis tissue other than hepatocellular carcinoma, $(\mathrm{J})$ hepatocellular carcinoma.

cant role in modulating the activities of Rho-like proteins in many cellular processes, such as cellular migration, invasion and adhesion (3). The Tiam1 protein with a length of 1591 amino acids comprises one $\mathrm{Db} 1$ homology (DH) domain, two Pleckstrin homology $(\mathrm{PH})$ domains, one myristylation site, two PEST domains, one coiled-coil (CC) domain, one Dlg homologous region (DHR) and one undefined region (EX) (3-5). The DH domain is catalyzes the activation of guanine nucleotide-dissociation stimulator (GDS) activity toward the Ras or Rho subfamily, whereas the PH domain is thought to mediate protein-protein interactions and is required for the biological functions of DH $(6,7)$. The $\mathrm{PH}$ domain forms a complex with the $\mathrm{CC}$ and EX domain, which together determine the membrane localization and part of the biological function of Tiam1 (5).

Habets et al found that Tiam1 transcripts were expressed not only in tumor cell lines of various origin, including B and $\mathrm{T}$ lymphomas, neuroblastoma and melanoma, but also in most normal tissues at different levels (2). Qi et al revealed a connection between Tiam1 overexpression and nasopha- 

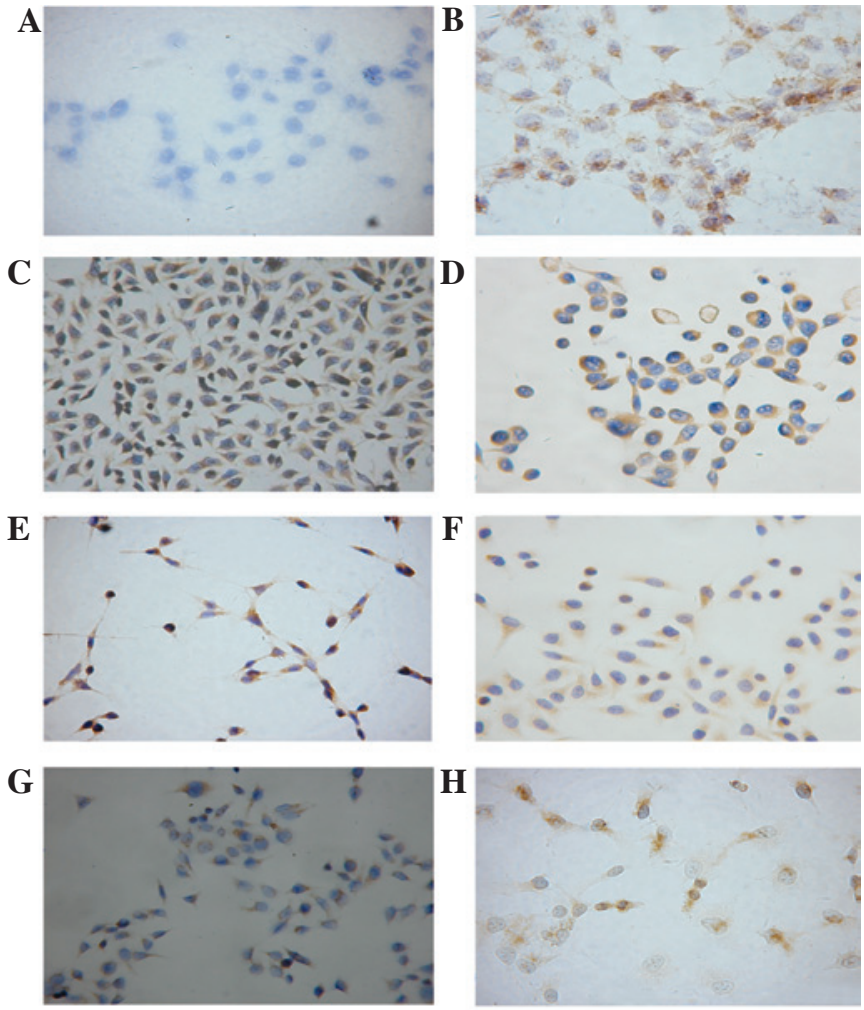

$\mathbf{I}$
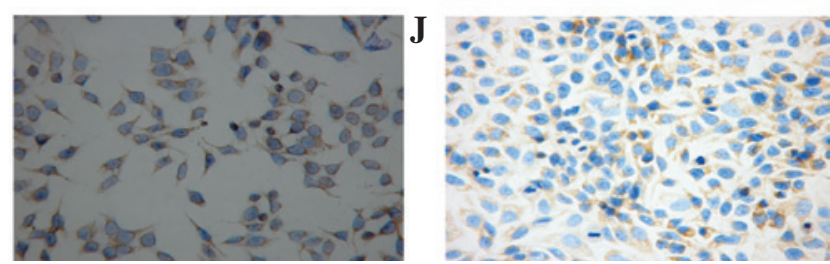

Figure 3. Expression of Tiam1 protein in human hepatocellular carcinoma cell lines and a normal primary human hepatocyte (original magnification, x200). (A) HL-7702, (B) Hep3B, (C) SMMC-7721, (D) QGy-7701, (E) QGy7703, (F) BEL-7402, (G) BEL-7404, (H) BEL-7405, (I) HepG2, (J) Huh-7.

ryngeal carcinoma. Elevated levels of Tiam1 expression have been correlated with lower disease-free and overall survival rates (8). Tiam1 has also been found to be significantly overexpressed in prostate carcinoma as well as pre-neoplastic high-grade prostatic intra-epithelial neoplasia lesions, and to be a negative predictor (9). Our previous study and those of others support the perspective that increased Tiam1 expression correlates with increased migration, invasion, adhesion and tumor progression properties of breast (10), colorectal $(11,12)$ and renal cell carcinomas (13). Although many studies have been carried out to examine the expression pattern of Tiam1, they have failed to present a comprehensive view of the gene expression profile with uniform criteria. To investigate further the physiological and pathological function of Tiam1, we first utilized a high throughput method (TMA) to systematically analyze the expression of Tiam1 in common tumor tissues and normal tissues. Consistent with previous reports, we found that Tiam1 was expressed ubiquitously in most adult tissues, but was more highly expressed in tissues with stong proliferation and multiplication capacities as well as in all analyzed tumor tissues. These results support the mainstream view that Tiam 1 is closely related to the cellular proliferation and multiplication process and oncogenesis.
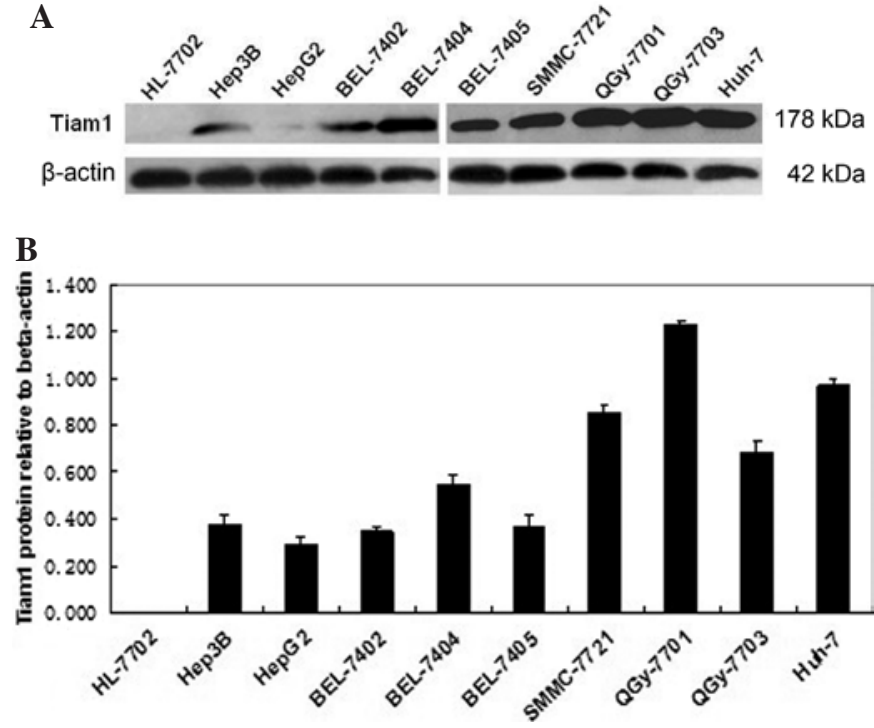

Figure 4. Detection of Tiam1 protein expression in human hepatocellular carcinoma cell lines and a normal primary human hepatocyte by Western blotting. $\beta$-actin was used as the protein loading control. (A) Tiam1 protein expression, (B) quantification data of Tiam1 protein expression.

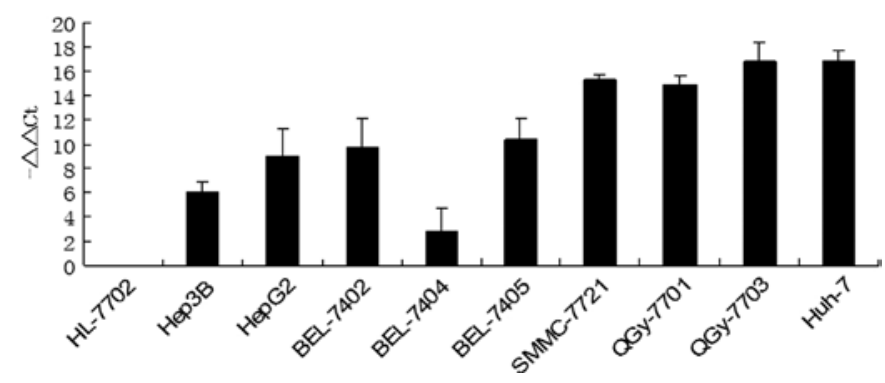

Figure 5. Expression level of Tiam1 gene in 9 hepatocellular carcinoma cell lines compared to a normal primary human hepatocyte by real-time PCR.

Tiam1, as a member of the GEFs family, activates scaffold protein IB2/JIP2 for the p38 mitogen-activated protein kinase cascade (14), as well as the scaffold spinophilin which promotes p70 S6 kinase activation (15). Activation of Rac by Tiam1 also promotes the adhesion and migration of Madin-Darby canine kidney cells $(16,17)$, while Tiam1 defects impair keratinocyte migration and reepithelialization by inhibiting $\alpha 3 \beta 1$-mediated laminin-5 deposition (18), enable cells to escape the mitotic arrest and transit more slowly, and facilitate chromosome congression errors (19). Cross-talks were found between Tiam1-Rac1 and the canonical Wnt-signaling pathways which result in Wnt target gene transcription enhancement $(20,21)$. Besides being associated with Par, Tiam1 forms a complex to control distinct forms of cellular polarity in different biological contexts (22). Src-mediated epithelial-mesenchymal transition requires Tiam1 phosphorylation and degradation following cell motility (23). Hence, the possible function of Tiam1 in oncogenesis, progression and metastasis has been confirmed by a series of experiments. The transfection of truncated Tiam1 cDNAs into non-invasive BW5147 T lymphoma cells made these cells invasive. Increased amounts of normal Tiam1 protein or protein truncation may induce this invasiveness (3). Mice lacking the Rac-specific activator Tiam1 are resistant 
to the development of Ras-induced skin tumors initiated with carcinogenic chemicals. Tumors produced in Tiam1deficient mice grew much slower than those in wild-type mice. Transfection of SP1 cells with Tiam1 cDNA promotes the binding of Tiam1 to CD44v3 and up-regulates HA/CD44v3mediated breast tumor migration (24), Also, Tiam1 deficiency impairs c-neu-induced mammary tumor formation in mice (25). The knock-down of Tiam1 results in reduced growth potential and adhesion abilities of human colorectal cancer cells (20). As shown in our results, the preferential overexpression of Tiam1 in malignant tumors suggests that Tiam1 is a significant tumor biomarker. Inhibitors targeting Tiam1 would have crucial therapeutic potential for the treatment of cancers. A novel small-molecule compound NSC23766 could effectively hinder the Rac1 binding and activation by Tiam1, and could thus impair the proliferation, anchorage-independent growth and invasion phenotypes. However, further investigation is required in order to confirm its pharmaceutical significance in applications (26).

Furthermore, we studied 3 surgical specimens of hepatoma. Compared to Tiam1 protein highly-expressing hepatoma tissue, para-carcinoma liver sclerotic tissue and proliferative interstitial tissue expressed Tiam1 in significantly weaker intensities and to a lesser extent. Moreover, parts of the cells in hyperplastic and degenerative hepatic tissue expressed Tiam1 positively, while normal hepatic tissue did not. These significant expression differences suggest that Tiam1 may serve a crucial role in the carcinogenesis and development of hepatoma. The specific mechanism invovled is worthy of further investigation. Detection of Tiam1 protein expression using the immunohistochemistry method would have diagnostic potential for the identification of hepatocellular carcinoma. Fluorescence quantitative PCR showed that differences in Tiam1 expression between the 9 hepatoma cell lines and a normal primary human hepatocyte were significant. Immunocytochemistry detection revealed a pattern of Tiam1 protein expression which was positive in both the membrane and cytoplasm of hepatoma cells. Data obtained from our laboratory has proven that Tiam1 is a prognostic marker for hepatocellular carcinoma (27). We therefore conclude that Tiam1, expressed in a broad range of malignancies, could be used as a potential target for the diagnosis and therapy of tumors, especially hepatoma. However, further studies are required in order to elucidate other signaling pathways involved in the the effect of Tiam1. However, as with other cancers (for example, K-Ras in colon tumor, EGFR in lung cancer), only a subset of hepatocellular carcinomas overexpress Tiam1. In addition, studies concentrating on the minimally invasive detection of other forms of Tiam 1 expression in peripheral blood would be of great interest.

\section{Acknowledgements}

This study was supported by the National Natural Science Foundation of China (no. 30801380, 81101822), the Guangdong Province Natural Science Foundation of China (No. 8151051501000027, 10451001002005047), the Innovation Fund Project for Graduate Students of Gaundong (Grant No. sybzzxm41) and the Guangzhou Science and Technology key Project (No. 11C26090521).

\section{References}

1. Habets GG, van der Kammen RA, Jenkins NA, Gilbert DJ, Copeland NG, Hagemeijer A and Collard JG: The invasioninducing TIAM1 gene maps to human chromosome band 21q22 and mouse chromosome 16. Cytogenet Cell Genet 70: 48-51, 1995.

2. Habets GG, van der Kammen RA, Stam JC, Michiels F and Collard JG: Sequence of the human invasion-inducing TIAM1 gene, its conservation in evolution and its expression in tumor cell lines of different tissue origin. Oncogene 10: 1371-1376, 1995.

3. Habets GG, Scholtes EH, Zuydgeest D, van der Kammen RA, Stam JC, Berns A and Collard JG: Identification of an invasioninducing gene, Tiam-1, that encodes a protein with homology to GDP-GTP exchangers for Rho-like proteins. Cell 77: 537-549, 1994.

4. Van Leeuwen FN, van der Kammen RA, Habets GG and Collard JG: Oncogenic activity of Tiam1 and Rac1 in NIH3T3 cells. Oncogene 11: 2215-2221, 1995.

5. Stam JC, Sander EE, Michiels F, van Leeuwen FN, Kain HE, van der Kammen RA and Collard JG: Targeting of Tiam1 to the plasma membrane requires the cooperative function of the $\mathrm{N}$-terminal pleckstrin homology domain and an adjacent protein interaction domain. J Biol Chem 272: 28447-28454, 1997.

6. Harlan JE, Hajduk PJ, Yoon HS and Fesik SW: Pleckstrin homology domains bind to phosphatidylinositol-4,5-bisphosphate. Nature 371: 168-170, 1994.

7. Musacchio A, Gibson T, Rice P, Thompson J and Saraste M: The PH domain: a common piece in the structural patchwork of signalling proteins. Trends Biochem Sci 18: 343-348, 1993.

8. Qi Y, Huang B, Yu L, Wang Q, Lan G and Zhang Q: Prognostic value of Tiam 1 and Racl overexpression in nasopharyngeal carcinoma. ORL J Otorhinolaryngol Relat Spec 71: 163-171, 2009.

9. Engers R, Mueller M, Walter A, Collard JG, Willers R and Gabbert HE: Prognostic relevance of Tiam1 protein expression in prostate carcinomas. Br J Cancer 95: 1081-1086, 2006.

10. Minard ME, Kim LS, Price JE and Gallick GE: The role of the guanine nucleotide exchange factor Tiam1 in cellular migration, invasion, adhesion and tumor progression. Breast Cancer Res Treat 84: 21-32, 2004.

11. Liu L, Wu DH and Ding YQ: Tiam1 gene expression and its significance in colorectal carcinoma. World J Gastroenterol 11: 705-707, 2005.

12. Minard ME, Ellis LM and Gallick GE: Tiam1 regulates cell adhesion, migration and apoptosis in colon tumor cells. Clin Exp Metastasis 23: 301-313, 2006 .

13. Zhao L, Liu Y, Sun X, He M and Ding Y: Overexpression of $\mathrm{T}$ lymphoma invasion and metastasis 1 predict renal cell carcinoma metastasis and overall patient survival. J Cancer Res Clin Oncol 137: 393-398, 2011.

14. Buchsbaum RJ, Connolly BA and Feig LA: Interaction of Rac exchange factors Tiam 1 and Ras-GRF1 with a scaffold for the p38 mitogen-activated protein kinase cascade. Mol Cell Biol 22: 4073-4085, 2002.

15. Buchsbaum RJ, Connolly BA and Feig LA: Regulation of p70 S6 kinase by complex formation between the Rac guanine nucleotide exchange factor (Rac-GEF) Tiam1 and the scaffold spinophilin. J Biol Chem 278: 18833-18841, 2003.

16. Sander EE, van Delft $S$, ten Klooster JP, Reid T, van der Kammen RA, Michiels F and Collard JG: Matrixdependent Tiam1/Rac signaling in epithelial cells promotes either cell-cell adhesion or cell migration and is regulated by phosphatidylinositol 3-kinase. J Cell Biol 143: 1385-1398, 1998.

17. Hordijk PL, ten Klooster JP, van der Kammen RA, Michiels F, Oomen LC and Collard JG: Inhibition of invasion of epithelial cells by Tiam1-Rac signaling. Science 278: 1464-1466, 1997.

18. Hamelers IH, Olivo C, Mertens AE, Pegtel DM, van der Kammen RA, Sonnenberg A and Collard JG: The Rac activator Tiam1 is required for (alpha)3(beta)1-mediated laminin-5 deposition, cell spreading, and cell migration. J Cell Biol 171: 871-881, 2005.

19. Woodcock SA, Rushton HJ, Castaneda-Saucedo E, Myant K, White GR, Blyth K, Sansom OJ and Malliri A: Tiam1-Rac signaling counteracts $\mathrm{Eg} 5$ during bipolar spindle assembly to facilitate chromosome congression. Curr Biol 20: 669-675, 2010.

20. Malliri A, Rygiel TP, van der Kammen RA, Song JY, Engers R, Hurlstone AF, Clevers $\mathrm{H}$ and Collard JG: The rac activator Tiam1 is a Wnt-responsive gene that modifies intestinal tumor development. J Biol Chem 281: 543-548, 2006. 
21. Buongiorno P, Pethe VV, Charames GS, Esufali S and Bapat B: Rac1 GTPase and the Rac1 exchange factor Tiam1 associate with Wnt-responsive promoters to enhance beta-catenin/ TCF-dependent transcription in colorectal cancer cells. Mo Cancer 7: 73, 2008.

22. Pegtel DM, Ellenbroek SI, Mertens AE, van der Kammen RA, de Rooij J and Collard JG: The Par-Tiam1 complex controls persistent migration by stabilizing microtubule-dependent frontrear polarity. Curr Biol 17: 1623-1634, 2007.

23. Woodcock SA, Rooney C, Liontos M, Connolly Y,Zoumpourlis V, Whetton AD, Gorgoulis VG and Malliri A: SRC-induced disassembly of adherens junctions requires localized phosphorylation and degradation of the rac activator tiam1. Mol Cell 33: 639-653, 2009.

24. Bourguignon LY, Zhu H, Shao L and Chen YW: CD44 interaction with tiam 1 promotes Racl signaling and hyaluronic acid-mediated breast tumor cell migration. J Biol Chem 275: 1829-1838, 2000.
25. Strumane K, Rygiel T, van der Valk M and Collard JG: Tiam1deficiency impairs mammary tumor formation in MMTV-c-neu but not in MMTV-c-myc mice. J Cancer Res Clin Oncol 135: 69-80, 2009.

26. Gao Y, Dickerson JB, Guo F, Zheng J and Zheng Y: Rational design and characterization of a Rac GTPase-specific small molecule inhibitor. Proc Natl Acad Sci USA 101: 7618-7623, 2004.

27. Ding Y, Chen B, Wang S, Zhao L, Chen J, Ding Y, Chen L and Luo R: Overexpression of Tiam1 in hepatocellular carcinomas predicts poor prognosis of HCC patients. Int J Cancer 124: 653-658, 2009. 